\title{
A global analysis of the comparability of winter chill models for fruit and nut trees
}

\author{
Eike Luedeling • Patrick H. Brown
}

Received: 9 February 2010 /Revised: 25 July 2010 /Accepted: 25 July 2010 / Published online: 22 August 2010

(C) The Author(s) 2010. This article is published with open access at Springerlink.com

\begin{abstract}
Many fruit and nut trees must fulfill a chilling requirement to break their winter dormancy and resume normal growth in spring. Several models exist for quantifying winter chill, and growers and researchers often tacitly assume that the choice of model is not important and estimates of species chilling requirements are valid across growing regions. To test this assumption, Safe Winter Chill (the amount of winter chill that is exceeded in $90 \%$ of years) was calculated for 5,078 weather stations around the world, using the Dynamic Model [in Chill Portions (CP)], the Chilling Hours $(\mathrm{CH})$ Model and the Utah Model [Utah Chill Units (UCU)]. Distributions of the ratios between different winter chill metrics were mapped on a global scale. These ratios should be constant if the models were strictly proportional. Ratios between winter chill metrics varied substantially, with the $\mathrm{CH} / \mathrm{CP}$ ratio ranging between 0 and 34 , the UCU/CP ratio between -155 and +20 and the $\mathrm{UCU} / \mathrm{CH}$ ratio between -10 and +5 . The models are thus not proportional, and chilling requirements determined in a given location may not be valid elsewhere. The Utah Model produced negative winter chill totals in many Subtropical regions, where it does not seem to be useful. Mean annual temperature and daily temperature range influenced all winter chill ratios, but explained only between 12 and $27 \%$ of the variation. Data on chilling requirements should
\end{abstract}

E. Luedeling $\cdot$ P. H. Brown

Department of Plant Sciences, University of California Davis,

Mail Stop Two, One Shields Ave,

Davis, CA 95616, USA

E. Luedeling $(\bowtie)$

World Agroforestry Centre (ICRAF),

United Nations Ave, Gigiri, P.O. Box 30677-00100,

Nairobi, Kenya

e-mail: e.luedeling@cgiar.org always be amended with information on the location and experimental conditions of the study in which they were determined, ideally including site-specific conversion factors between winter chill models. This would greatly facilitate the transfer of such information across growing regions, and help prepare growers for the impact of climate change.

Keywords Chilling Hours · Chilling requirement . Chill Portions · Dynamic Model $\cdot$ Utah Model $\cdot$ Winter chill

\section{Introduction}

Winter chill is essential for most perennial plants from cold climates (Erez 2000; Knight 1801; Samish 1954; Saure 1985; Vegis 1961). In order to avoid frost damage in the winter, such deciduous plants fall dormant in the fall and do not resume growth until a certain amount of winter chill has accumulated, fulfilling their chilling requirement. In spite of more than two centuries of research on the breaking of dormancy (starting with Knight 1801), the physiological and genetic processes occurring in trees during winter chill accumulation are poorly understood. Models of winter chill accumulation are thus purely empirical and based on either field observations (e.g., Linkosalo et al. 2008) or controlled temperature experiments (e.g., Fishman et al. 1987a) rather than on a functional understanding of tree physiology.

The study of plant phenology and how it responds to temperature is becoming increasingly important in the context of observed and future projected temperature increases (Chuine et al. 2010; Hudson 2010; Körner and Basler 2010). Many authors have reported on spring phenology changes in a wide range of species (e.g. Chmielewski and Rötzer 2001; Garcia-Mozo et al. 2010; 
Menzel et al. 2006; Schwartz 1999), and such changes are likely to continue, since all major climate models project progressively rising temperatures (IPCC 2007). Insufficient knowledge of species chilling requirements and a lack of accurate winter chill models are major limiting factors for the accuracy of projections of climate change effects on deciduous vegetation.

The desire to expand the production of deciduous fruits and nuts into warmer regions has motivated a lot of horticultural research on winter chill (e.g., Erez et al. 1990; Richardson et al. 1974; Weinberger 1950). Many commercially important fruit and nut trees, such as apples, pears, cherries, peaches, walnuts and almonds, require winter chill, and growers around the world select their tree cultivars according to the amount of winter chill they expect at their production sites. This selection process requires quantification of available winter chill and species chilling requirements, and a range of models have been developed for this purpose (e.g., Chandler 1942; Erez et al. 1990; Richardson et al. 1974). However, it is often historic precedence rather than systematic research that determines which model is used in a given growing region. Studies on winter chill and chilling requirements often tacitly assume that the choice of the model is not important, and that all models can be used interchangeably. Information about the chilling requirement of a given tree cultivar is thus often assumed to be valid in different locations, and summary tables of chilling requirements rarely specify where the data was obtained.

Recent research suggests that models may not be interchangeable (Luedeling et al. 2009d, e; Ruiz et al. 2007; Viti et al. 2010). Subjecting four common horticultural winter chill models to the same projected temperature changes for California, Luedeling et al. (2009d) showed that, depending on which model was used, winter chill changes between 1950 and 2050 ranged from -22 to $-46 \%$. This study showed substantial variation in the sensitivity of the tested models to climate change. Consequently, projections of winter chill that use the most sensitive Chilling Hours Model have projected rather dramatic declines in future winter chill in warm regions (Baldocchi and Wong 2008; Luedeling et al. 2009b), whereas changes indicated by the less sensitive Dynamic Model tend to be much less severe (Luedeling et al. 2009c, d). Compared to projected changes in warm regions, historical winter chill changes in relatively cool Germany were moderate, and differences between the Chilling Hours Model and the Dynamic Model were less pronounced (Luedeling et al. 2009a). Luedeling et al. (2009e) analyzed ratios between total accumulated winter chill during entire winter seasons, as calculated with different winter chill models, for eight locations in California and for all years between 1952 and 2008. Ratios varied substantially between locations and between years.
Particularly strong differences were detected between temperature regimes prevailing in a cold chamber (constant temperatures of $6^{\circ} \mathrm{C}$ ) and ambient orchard temperatures, indicating that chilling requirements determined by exposing trees to constant low temperatures may not be valid under field conditions (Luedeling et al. 2009e).

It thus appears that the choice of the model that is used for quantifying winter chill is important, and that assuming that chilling requirements determined in a given location are valid elsewhere is problematic. Nevertheless, converting between units of different models using site-specific conversion factors may be possible. At present, however, site-specific conversion factors have been determined only for a few locations and there is no information on the variability of these factors around the world. The objective of this paper is to assess the comparability of several winter chill models and to determine site-specific conversion factors, based on a global temperature dataset.

\section{Materials and methods}

\section{Weather data}

Daily temperature and precipitation records were downloaded for all 11,361 available weather stations at the National Climatic Data Center (NCDC 2008). This dataset was filtered, removing all stations that had less than 5,000 daily records between 1973 and 2002, and excluding all stations with more than $25 \%$ of daily minimum or maximum temperatures or $50 \%$ of daily rainfall data missing. For the remaining 5,078 weather stations, all available temperature and precipitation records were used to calculate site parameters for use in the LARS-WG stochastic weather generator (Semenov 2008). This tool describes the weather at a given location in statistical terms, with separate statistics for observed dry and wet periods. This information can then be used to generate synthetic weather records for the site. For each station, we evaluated the entire weather record for all days between 1973 and 2002, calculating separate linear regression equations for minimum temperature, maximum temperature and precipitation for each month of the year. Based on these regression analyses, we developed a climate scenario representing typical climatic conditions for the year 2000 . This scenario contains the typical deviation of monthly minimum and maximum temperatures and precipitation from the mean of the calibration period (1973-2002) for each station, as calculated by the regression equations. Using the weather generator, we then generated 101 years of synthetic weather data for the '2000' scenario. This data set can be interpreted as 101 replicates of temperature and precipitation for the year 2000, with a random seed 
introducing variability that corresponds to variability observed during the calibration period. For each weather station and each day of the 101-year period for each scenario, hourly temperatures were then generated using the idealized temperature curve proposed by Linvill (Linvill 1990; Luedeling et al. 2009a). Linvill's equations, which use a sine curve for daytime temperatures and a logarithmic decline curve for nighttime cooling, require sunset and sunrise hours, as well as daylength, as input parameters. These data were generated using the equations of Spencer (1971) and Almorox et al. (2005). Resulting from these processing steps were 101 years of continuous hourly weather records for each weather station, representing typical climatic conditions around the year 2000 .

Winter chill models

We calculated winter chill using three important winter chill models: (1) the Chilling Hours Model, 2) the Utah Model and 3) the Dynamic Model. The Chilling Hours Model (Chandler 1942) is the oldest method to quantify winter chill that is still widely used. It considers all hours with temperatures between 0 and $7.2^{\circ} \mathrm{C}$ as equally effective for winter chill accumulation. The number of Chilling Hours at time $\mathrm{t}\left(\mathrm{CH}_{\mathrm{t}} ; \mathrm{t}\right.$ is measured in hours since the start of the dormancy season) can be calculated as:

$\mathrm{CH}_{t}=\sum_{i=1}^{t} T_{7.2}$, with $T_{7.2}= \begin{cases}0^{\circ} \mathrm{C}<T<7.2^{\circ} \mathrm{C} & : 1 \\ \text { else } & : 0\end{cases}$

The Utah Model (Richardson et al. 1974) contains a weight function assigning different chilling efficiencies to different temperature ranges, including negative contributions by high temperatures. While a few modified versions of the weight function exist, we only used the weights from the original publication (Richardson et al. 1974), which are most widely used. The number of Utah Chill Units at time $t$ $\left(\mathrm{UCU}_{\mathrm{t}}\right)$ can be expressed as:

$$
\begin{aligned}
U C U_{t}= & \sum_{i=1}^{t} T_{U}, \text { with } T_{U} \\
= & \begin{cases}T \leq 1.4^{\circ} C & : 0 \\
1.4^{\circ} C<T \leq 2.4^{\circ} C & : 0.5 \\
2.4^{\circ} C<T \leq 9.1^{\circ} C & : 1 \\
9.1^{\circ} C<T \leq 12.4^{\circ} C & : 0.5 \\
12.4^{\circ} C<T \leq 15.9^{\circ} C & : 1 \\
15.9^{\circ} C<T \leq 18.0^{\circ} C & :-0.5 \\
T \geq 18.0^{\circ} C & : 1\end{cases}
\end{aligned}
$$

The Dynamic Model (Erez et al. 1990; Fishman et al. 1987a, b), which was originally developed for the warm winters in Israel, takes a different approach to quantifying winter chill. It assumes that winter chill results from a twostep process, in which an intermediate product is first formed in a process promoted by cold temperatures. Warm temperatures can destroy this intermediate product. As soon as a certain quantity of intermediate has accumulated, it is irreversibly transformed into a Chill Portion, which can no longer be destroyed. The equations for the number of Chill Portions at time $\mathrm{t}\left(\mathrm{CP}_{\mathrm{t}}\right)$ are:

$$
\begin{array}{r}
x_{i}=\frac{e^{\text {slptetmlt } \cdot \frac{T_{K}-\text { tetmlt }}{T_{K}}}}{1+e^{\text {slp.tetmlt } \cdot \frac{T_{K}-\text { tetmlt }}{T_{K}}}} \\
x_{S}=\frac{a_{0}}{a_{1}} \cdot e^{\frac{e_{1}-e_{0}}{T_{K}}} \\
a k_{1}=a_{1} \cdot e^{-\frac{e_{1}}{T_{K}}} \\
\text { inter }_{E}=x_{S}-\left(x_{S}-\text { inter }_{S}\right) \cdot e^{-a k_{1}}
\end{array}
$$

inter $_{S}= \begin{cases}t=t_{0} & : 0 \\ t>t_{0} \wedge \text { inter }_{E_{t-1}}<1 & : \text { inter }_{E_{t-1}} \\ t>t_{0} \wedge \text { inter }_{E_{t-1}} \geq 1 & : \text { inter }_{E_{t-1}} \cdot\left(1-x_{i}\right)\end{cases}$

delt $= \begin{cases}t=t_{0} & : 0 \\ t>t_{0} \wedge \text { inter }_{E}<1 & : 0 \\ t>t_{0} \wedge \text { inter }_{E} \geq 1 & : x_{i} \cdot \text { inter }_{E}\end{cases}$

$C P_{t}= \begin{cases}t=t_{0} & : \text { delt } \\ t \geq t_{0} & : \text { delt }+C P_{t-1}\end{cases}$

The experimentally derived constants slp, tetmlt, $a_{0}, a_{1}, e_{0}$ and $e_{1}$ were set to $1.6,277,139,500,2.567 \times 10^{18}, 4,153.5$ and $12,888.8$, respectively, according to standard practice in horticultural applications. While it was the original intention of the model developers that constants be adjusted for each species and cultivar (Fishman et al. 1987a, b), this does not happen often in practice, and we therefore used only the commonly used values for all parameters.

Various other models, such as the Positive Utah Model (Linsley-Noakes and Allan 1994) or the North Carolina Model (Shaltout and Unrath 1983) were developed for the climatic conditions of specific regions and are not often used outside those regions. We therefore did not include these models in this study.

The units of the various models are Chilling Hours $(\mathrm{CH})$ for the Chilling Hours Model, Utah Chill Units (UCU) for the Utah Model, and Chill Portions (CP) for the Dynamic Model. Winter chill was calculated for each of these models for all 101 years of all 5,078 weather stations, resulting in data for 100 winter seasons per station. Winter chill was summarized for the time period between 1 October and 1 May for all stations in the 
Fig. 1 Global distribution of Safe Winter Chill, calculated with the Dynamic Model, the Chilling Hours Model and the Utah Model. The spatial interpolation is based on 5,078 point estimates at weather station locations, with poor coverage in the shaded areas (more than $4^{\circ}$ distance from closest weather station)
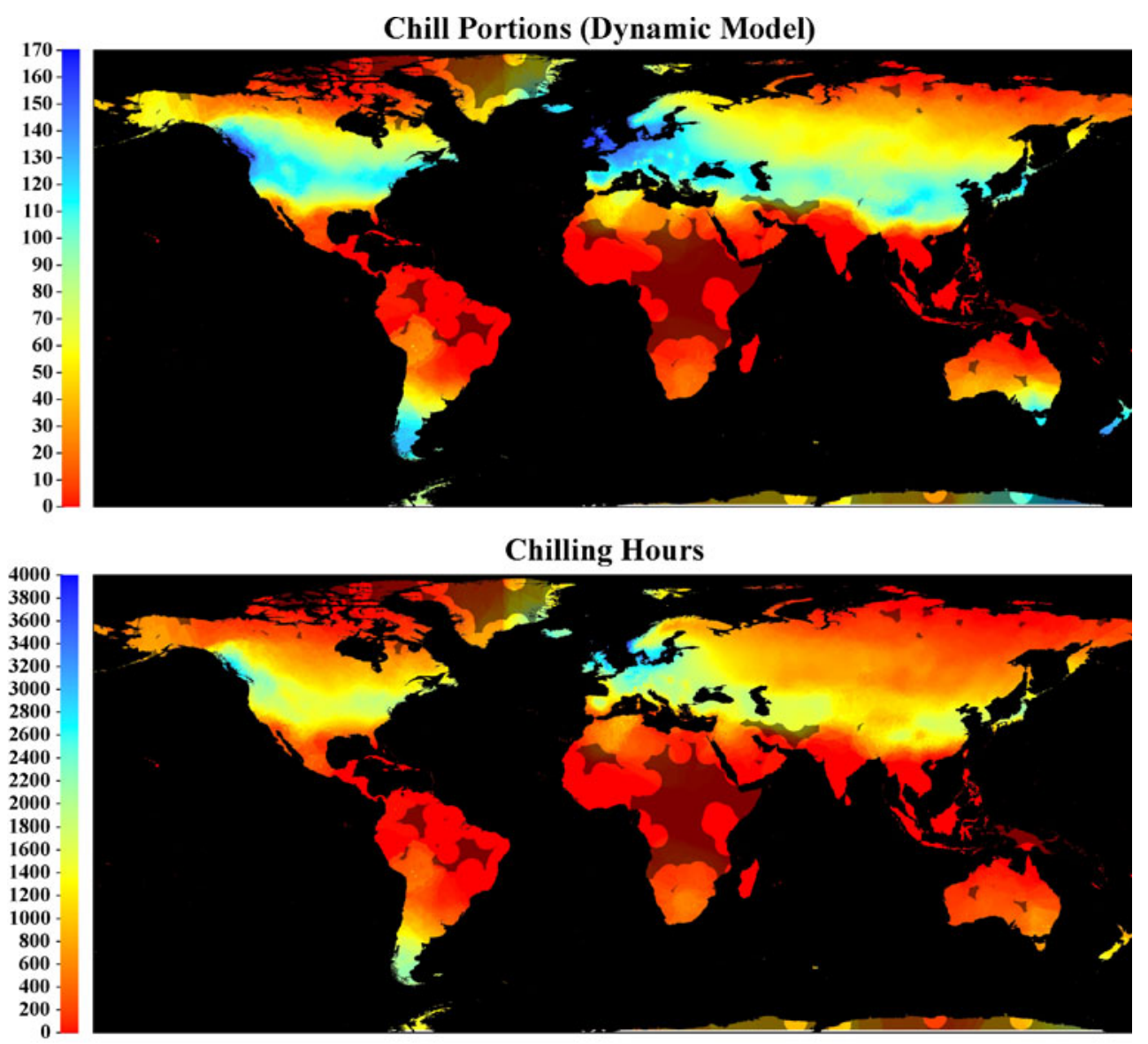

Utah Chill Units

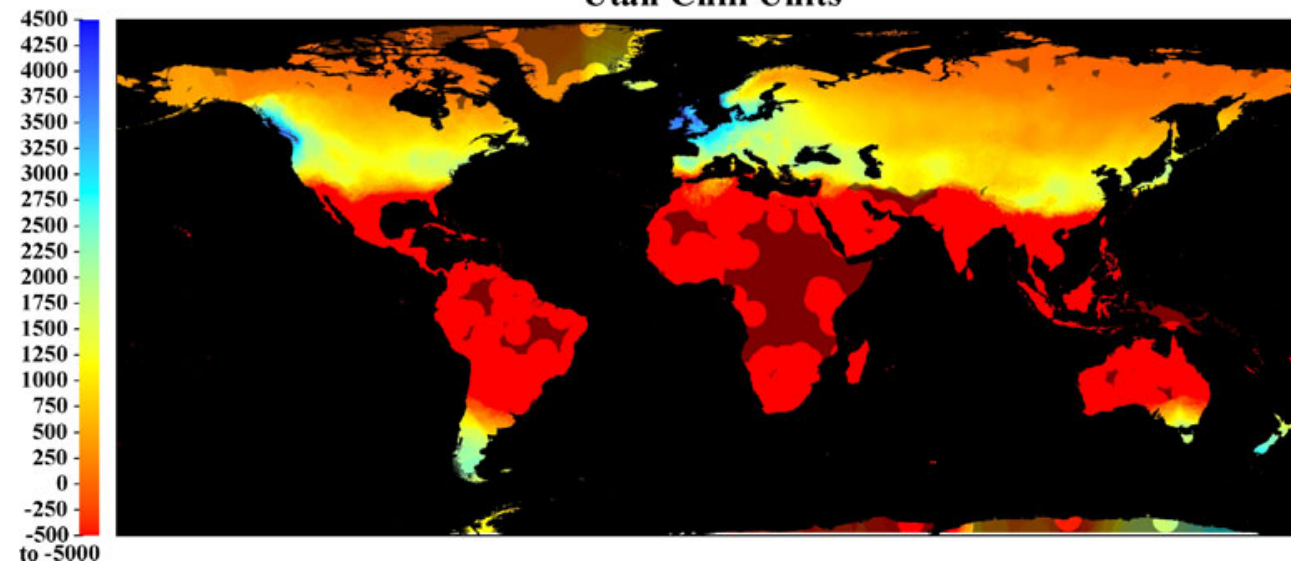

Northern Hemisphere, and between 1 April and 1 November for stations in the South. For each station, we then calculated Safe Winter Chill, which is defined as the $10 \%$ quantile of the resulting distribution over all 100 winters on record (Luedeling et al. 2009c). This metric defines the minimum amount of winter chill that growers of fruit and nut trees can expect in $90 \%$ of all years. It can be interpreted as the maximum recommendable chilling requirement of tree species or cultivars grown in a given location. Species or cultivars with chilling requirements that are higher than locally available Safe Winter Chill are likely to not fulfill these requirements in more than $10 \%$ of years, which may render their production uneconomical. For all combinations of two winter chill models, we then calculated the ratios between Safe Winter Chills as calculated with the two models, for each weather station location. Ratios were calculated between Chilling Hours and Chill Portions (CH/CP), between Utah Chill Units and Chill Portions (UCU/CP) and between Utah Chill Units and Chilling Hours (UCU/CH).

For two winter chill models to be proportional, this ratio should be constant regardless of the location of the weather station. To avoid spurious outliers in calculated ratios, only 
Fig. 2 Correlations between Safe Winter Chill estimates, based on calculations for 5,078 weather stations around the world with three winter chill models. Box plots on the right show the distribution of ratios between the same two winter chill metrics among all weather stations
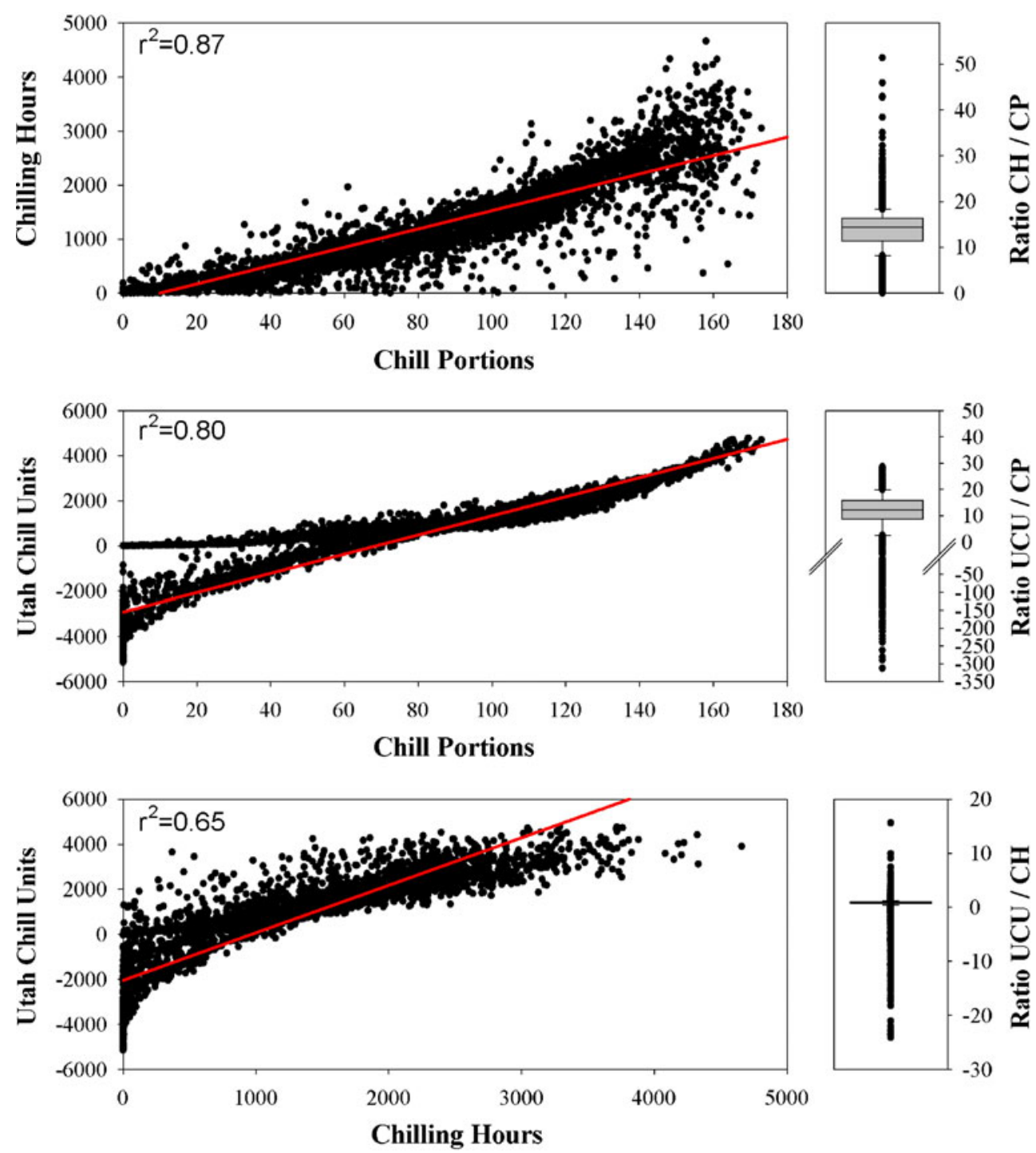

denominators of $>100 \mathrm{CH}$ or $>10 \mathrm{CP}$ were accepted. All calculations were programmed in JSL, the scripting language of JMP 8 (SAS Institute, Cary, NC). Using ArcGIS (ESRI, Redlands, CA), all data were spatially interpolated to a 0.1 degree resolution using 12-neighbor Kriging with a spherical semivariogram. In all maps, areas that were more than $4^{\circ}$ away from the closest weather station were shaded out, since interpolations for these areas are unreliable. For ten major growing regions of Mediterranean fruits and nuts, means and standard deviations of winter chill metric ratios were summarized using spatial statistics.

Factors influencing winter chill ratios

The two main factors that have led researchers and growers to prefer one winter chill model over another are mean temperature of the site and continentality. For each climate scenario, we therefore calculated the mean temperature for every weather station based on the 101-year synthetic hourly weather records. As a proxy for continentality, we used the mean daily temperature range, calculated as the difference between mean daily maximum and minimum temperature over the entire temperature record. Effects of mean temperature and mean daily temperature range on winter chill metric ratios were determined by two-way analysis of variance with interaction (JMP 8, SAS Institute).

\section{Results}

Spatial distribution of Safe Winter Chill

Safe Winter Chill varied substantially around the world, for all three winter chill metrics analyzed (Fig. 1). According to the Dynamic and Utah Models, Safe Winter Chill was highest in the maritime climates around the North Sea in Europe, along the Pacific Coast of Oregon 


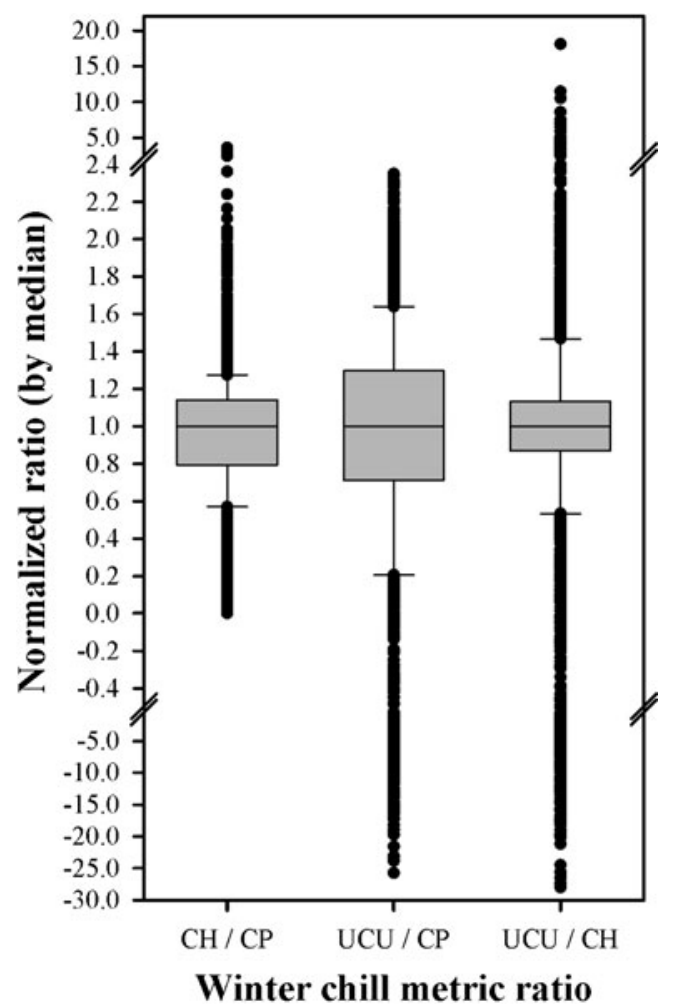

Fig. 3 Ratios between the three Safe Winter Chill metrics, normalized by the median of the distributions among all 5,078 weather stations

(US), Washington (US) and British Columbia (Canada), and on New Zealand's South Island, where it exceeded $130 \mathrm{CP}$ or 2,500 UCU, respectively. Safe Winter Chill of more than 2,000 CH was registered around the North Sea in Europe, in Washington and British Columbia, in Southern Chile and Argentina, and in the northern half of Honshu Island (Japan).

Intermediate Safe Winter Chill (70-130 CP; 700-2,000 $\mathrm{CH} ; 700-2,000 \mathrm{UCU})$ in the Northern Hemisphere prevails in most of the continental United States and Southern
Canada, as well in a long strip spanning most of Europe, and extending throughout Central Asia and into China and Japan. In the Southern Hemisphere, regions of intermediate winter chill are much scarcer, and exist only at the Southern tip of South America and in Southeastern Australia, as well as likely in the higher reaches of the Andes, where no useable weather stations were located. Regions with low Safe Winter Chill (30-70 CP; 300-700 CH; -1,000-700 $\mathrm{UCU}$ ) were detected in most Subtropical regions, as well as at high latitudes adjacent to the intermediate Safe Winter Chill regions. In spite of sufficient Safe Winter Chill, the latter areas are unlikely to be suitable for fruit and nut production due to very cold winters and lack of heat in the summer. All three winter chill models identified virtually no Safe Winter Chill in the Tropics.

\section{Differences among models}

For some combinations of two winter chill models, correlations between Safe Winter Chills were fairly good, with coefficients of determination between 0.65 and 0.87 , but ratios between different winter chill metrics varied substantially in all cases (Fig. 2). Normalizing all Safe Winter Chill ratio distributions by the median illustrates that there is no clearly defined and globally valid conversion factor between the models (Fig. 3). For example, while the median of the ratio distribution was 14.4, one Chill Portion could correspond to anywhere between 0 and $51 \mathrm{CH}$, depending on local climate. While these are the extreme cases, $50 \%$ of all weather stations had $\mathrm{CH} / \mathrm{CP}$ ratios of $>16.4$ or $<11.4$. For half of all weather stations, a chilling requirement of $70 \mathrm{CP}$ would thus correspond to between 800 and $1,150 \mathrm{CH}$. For $80 \%$ of all stations, the corresponding number of $\mathrm{CH}$ would be between 570 and 1,281 (CH / CP of 8.2 and 18.3, respectively). Even between growing regions with seemingly similar climate and comparable tree species distribu-

Table 1 Variation of Safe Winter Chill ratios within and between major growing regions of Mediterranean fruit and nut trees. For each region and ratio, means and standard deviations are given. $C H$ Chilling Hours, UCU Utah Chill Units, CP Chill Portions

\begin{tabular}{|c|c|c|c|}
\hline Region & $\mathrm{CH} / \mathrm{CP}$ & $\mathrm{UCU} / \mathrm{CP}$ & $\mathrm{UCU} / \mathrm{CH}$ \\
\hline California - Central Valley & $13.0 \pm 0.8$ & $8.9 \pm 5.3$ & $0.6 \pm 0.8$ \\
\hline Northern Mexico & $15.5 \pm 1.6$ & $-14.3 \pm 18.8$ & $-1.1 \pm 1.3$ \\
\hline Southeastern US (Carolinas, Georgia, Northern Florida) & $14.4 \pm 1.0$ & $-10.4 \pm 27.1$ & $-0.7 \pm 2.0$ \\
\hline Chile & $14.8 \pm 0.8$ & $5.5 \pm 11.2$ & $0.6 \pm 0.6$ \\
\hline South Africa - Western Cape & $8.9 \pm 1.1$ & $-17.8 \pm 0.7$ & $-2.9 \pm 0.3$ \\
\hline Maghreb (Morocco, Tunisia, Northern Algeria) & $9.5 \pm 1.7$ & $-14.9 \pm 9.8$ & $-1.6 \pm 1.0$ \\
\hline Israel & $7.0 \pm 1.2$ & $-23.8 \pm 5.2$ & $-0.5 \pm 0.5$ \\
\hline Northwestern Mediterranean (Portugal, Spain, Southern France, Italy) & $11.3 \pm 2.9$ & $11.9 \pm 9.1$ & $1.1 \pm 0.6$ \\
\hline South Australia & $7.2 \pm 1.9$ & $-13.1 \pm 14.7$ & $-0.3 \pm 1.2$ \\
\hline New Zealand & $8.3 \pm 1.1$ & $15.8 \pm 2.7$ & $3.2 \pm 0.1$ \\
\hline
\end{tabular}


Fig. 4 Global distributions of ratios between two Safe Winter Chill metrics, including winter chill estimates by the Dynamic Model, the Chilling Hours Model and the Utah Model. The spatial interpolation is based on 5,078 point estimates at weather station locations, with poor coverage in the shaded areas
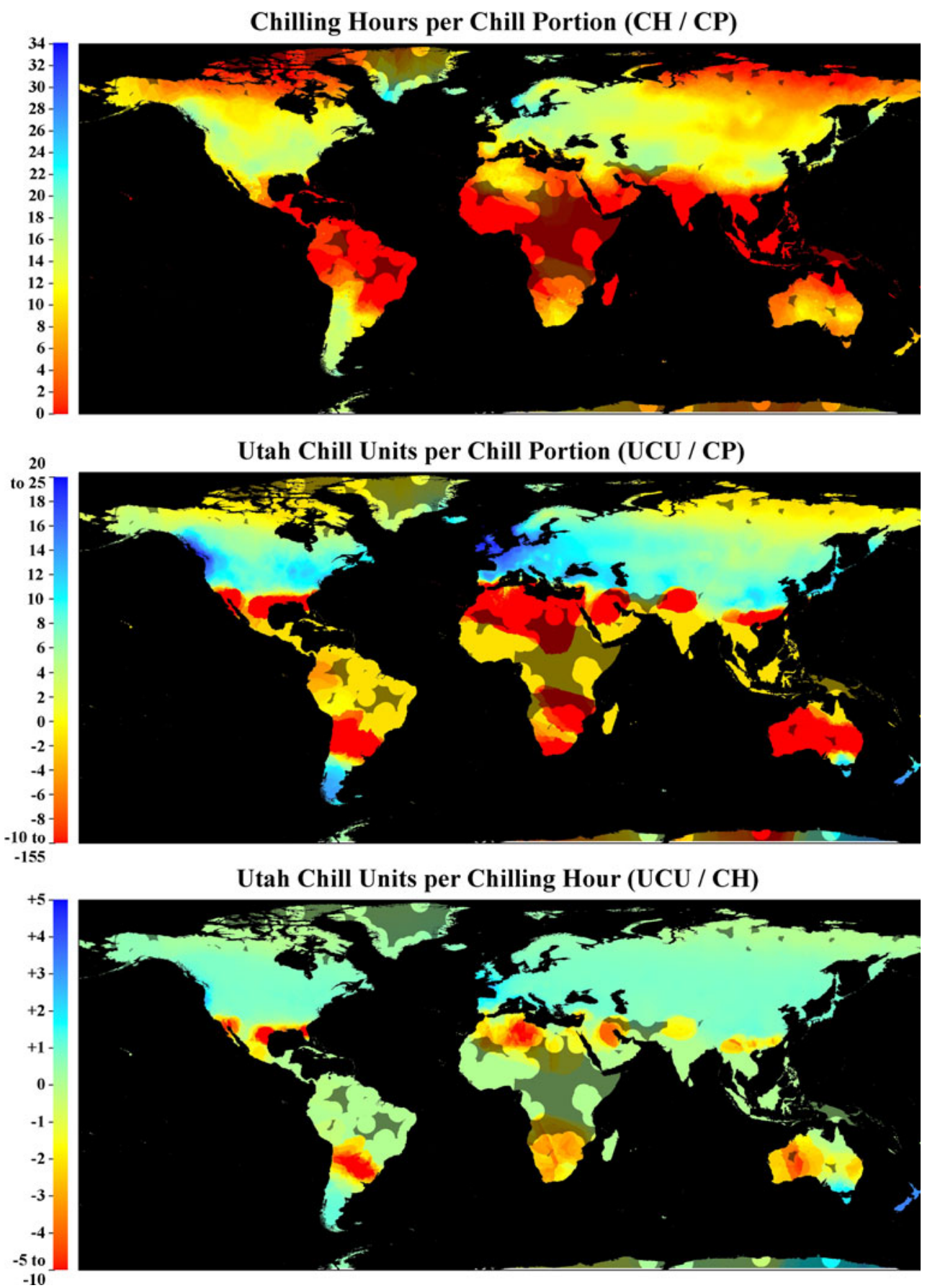

tions, and even within these regions, winter chill metric ratios varied substantially, as shown in Table 1 for some major producing regions of Mediterranean fruits and nuts.

This large variation illustrates the problems inherent in using an inappropriate winter chill model combined with estimates of a tree's chilling requirement determined in a location with a different climate. To allow meaningful conversions between winter chill metrics, the conversion factors need to be specified based on climatic attributes of the growing region where the models are applied.
Patterns in winter chill metric ratios

Analyzing the geographic distribution of Safe Winter Chill ratios reveals clear spatial patterns (Fig. 4). Generally, ratios between $\mathrm{CH}$ and $\mathrm{CP}$, as well as between UCU and CP, were highest at temperate latitudes, and often substantially lower towards the poles and Subtropics. The ratio of $\mathrm{CH}$ per $\mathrm{CP}$ increased gradually from 0 in the Tropics and boreal regions to more than 25 in parts of Scandinavia and Greenland. All ratios that included the Utah Model were 
Table 2 Results of the two-way analysis of variance with interaction between the factors mean temperature $\left(T_{\text {mean }}\right)$ and mean daily temperature range $\left(T_{\text {range }}\right)$ and the Safe Winter Chill ratios $(\mathrm{CH} / \mathrm{CP}, \mathrm{UCU} / \mathrm{CP}$ and $\mathrm{UCU} / \mathrm{CH}) . R M S E$ Root mean square error

\begin{tabular}{|c|c|c|c|}
\hline \multicolumn{2}{|l|}{ Summary of fit } & \multicolumn{2}{|l|}{ Parameter estimates } \\
\hline $\mathrm{R}^{2}$ & 0.27 & Intercept & $17.32 \pm 0.23$ \\
\hline Mean of response & 13.79 & $T_{\text {mean }}$ & $-0.05 \pm 0.01$ \\
\hline RMSE & 3.89 & $T_{\text {range }}$ & $-0.30 \pm 0.02$ \\
\hline $\mathrm{N}$ & 4,170 & $\left(T_{\text {mean }}-8.61\right) \times\left(T_{\text {range }}-10.05\right)$ & $0.10 \pm 0.00$ \\
\hline ANOVA $P$ value & $<0.0001$ & & \\
\hline \multicolumn{4}{|l|}{$\mathrm{UCU} / \mathrm{CP}$} \\
\hline Summary of fit & & Parameter estimates & \\
\hline $\mathrm{R}^{2}$ & 0.12 & Intercept & $30.90 \pm 1.37$ \\
\hline Mean of response & 7.74 & $T_{\text {mean }}$ & $-1.11 \pm 0.05$ \\
\hline RMSE & 23.47 & $T_{\text {range }}$ & $-1.36 \pm 0.12$ \\
\hline $\mathrm{N}$ & 4,170 & $\left(T_{\text {mean }}-8.61\right) \times\left(T_{\text {range }}-10.05\right)$ & $-0.02 \pm 0.01$ \\
\hline ANOVA $P$ value & $<0.0001$ & & \\
\hline \multicolumn{4}{|l|}{$\mathrm{UCU} / \mathrm{CH}$} \\
\hline Summary of fit & & Parameter estimates & \\
\hline $\mathrm{R}^{2}$ & 0.17 & Intercept & $2.53 \pm 0.11$ \\
\hline Mean of response & 0.57 & $T_{\text {mean }}$ & $-0.07 \pm 0.00$ \\
\hline RMSE & 1.82 & $T_{\text {range }}$ & $-0.14 \pm 0.01$ \\
\hline $\mathrm{N}$ & 4,066 & $\left(T_{\text {mean }}-8.56\right) \times\left(T_{\text {range }}-10.14\right)$ & $-0.02 \pm 0.00$ \\
\hline ANOVA $P$ value & $<0.0001$ & & \\
\hline
\end{tabular}

negative in the growing regions of the warm Subtropics (Fig. 4). This indicates that, when winter chill is quantified in UCU, fruit and nut trees in these regions would have negative chilling requirements.

Influence of temperature and continentality on winter chill metric ratios

The ratios between different winter chill metrics clearly varied with mean daily temperature of the site $\left(T_{\text {mean }}\right)$ and mean daily temperature range ( $T_{\text {range}} ;$ Table 2$)$. The relationships are not very well defined, as evidenced by low coefficients of determination, and visual interpretation of the relationships between Safe Winter Chill metric ratios and the individual factors shows the potentials and limitations of conversion between models more clearly (Fig. 5).

None of the Safe Winter Chill metric ratios were constant over the whole range of mean temperatures or temperature ranges. All calculated ratios showed strong shifts between mean temperatures of -10 and about $8^{\circ} \mathrm{C}$ and erratic behavior at higher temperatures. The response to $T_{\text {range }}$ was much less clearly defined, but was characterized by decreasing ratios with increasing $T_{\text {range. }}$.

\section{Discussion}

All ratios between winter chill metrics varied substantially around the globe, showing clearly that the models are not proportional. There are large regions of relatively homogeneous Safe Winter Chill ratios, but in those areas where winter chill is most critical, in the warmer growing regions, ratios vary even over relatively short distances. This strongly suggests that a given tree cultivar may not require the same number of $\mathrm{CH}$ or UCU when grown in different climatic zones. This is particularly problematic when transferring tree species or cultivars from temperate to Subtropical growing regions. Especially in Mediterranean climates, conversion factors between models differed greatly, in particular for ratios that include the Utah Model, with its winter chill negation mechanism (Table 1). For 


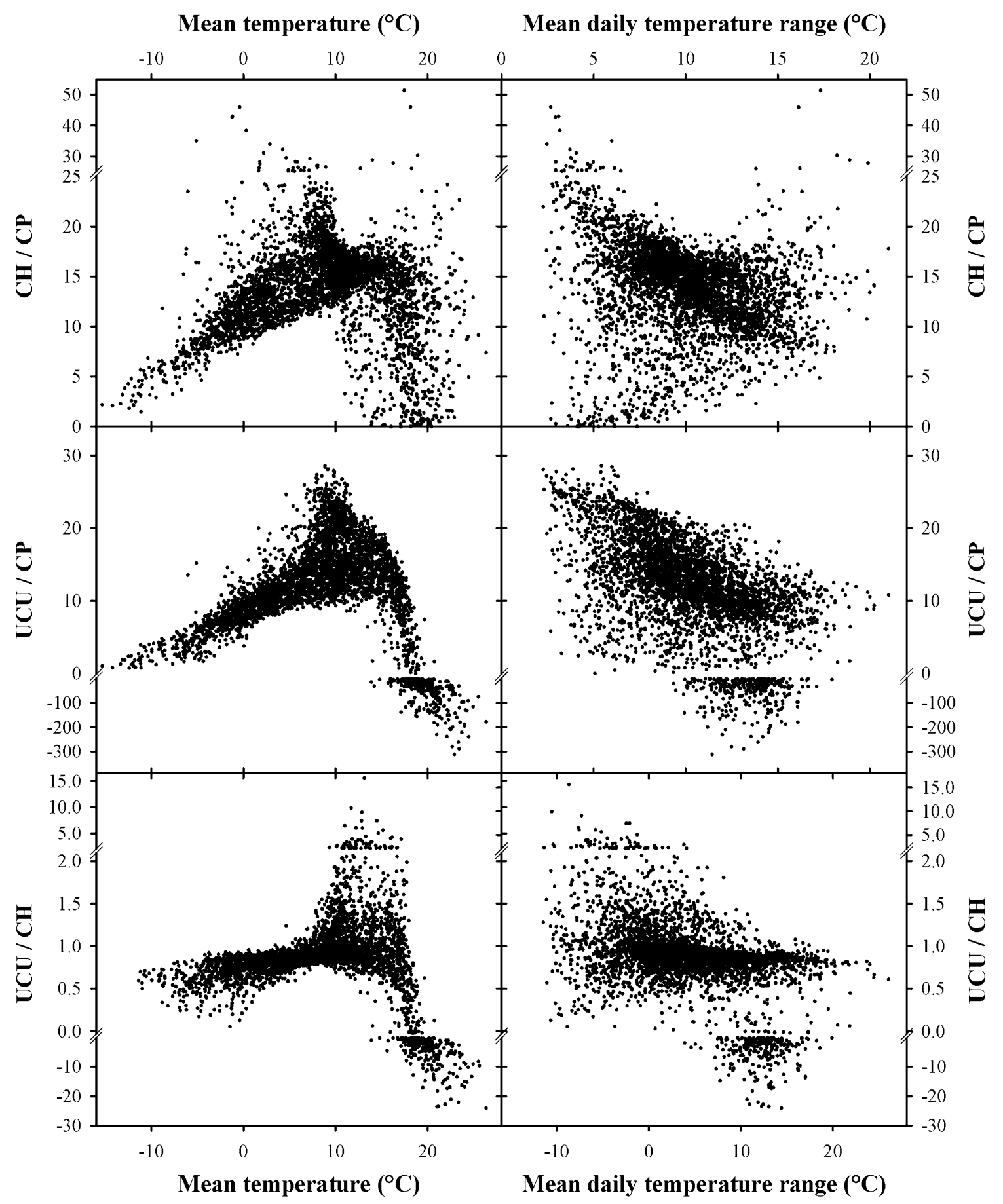

Fig. 5 Relationship of all calculated Safe Winter Chill ratios with mean temperature and mean daily temperature range

areas with mean temperatures above approximately $12^{\circ} \mathrm{C}$, chill negation is clearly overemphasized, resulting in negative conversion factors, even in major growing regions, such as the Mediterranean region or South Africa.

To our knowledge, all studies comparing the accuracy of winter chill models that included the Dynamic Model have found this model to be superior or equivalent to all other models. Evidence has been presented for Israel (Erez 2000; Erez et al. 1990; Fishman et al. 1987a, b), South Africa (Allan et al. 1995, 1997; Erez et al. 1990; Gardner and Bertling 2005), Chile (Perez et al. 2008), France (Balandier et al. 1993), Spain (Alburquerque et al. 2008; Ruiz et al. 2006, 2007) and California (Luedeling et al. 2009e). All horticultural winter chill models, including the Dynamic 
Model, fail to explain peach phenology in the Tropical climate of Réunion Island (Balandier et al. 1993), and none of the models allow reliable prediction of spring phenology (Luedeling et al. 2009e), indicating that no model perfectly describes tree physiology. Phenology modeling strategies from other disciplines, such as the Unified Model (Chuine 2000), have been successful in explaining budburst of temperate trees, after detailed calibration with observed phenology over many years or locations, but these models do not provide generally applicable chilling functions that can be used in warmer regions. Among the three winter chill models tested in this study, the Dynamic Model seems most accurate in warmer climates. We are not aware of any tests of the applicability of this model in cold or temperate regions. For such regions, however, the conversion factors between the winter chill metrics are much more homogeneous than in the Subtropics, indicating that conversion between winter chill models is possible there at relatively predictable conversion factors. These factors can be estimated based on mean annual temperature, but site-specific calibration is clearly preferable due to much variation that is not explained by mean temperature or temperature range (Fig. 5).

Assuming for the purpose of this discussion that the Dynamic Model is really the best existing model for most growing regions (as the previous discussion suggests but cannot prove without further testing), it would be preferable to specify the chilling requirements of all tree cultivars in $\mathrm{CP}$ rather than $\mathrm{CH}$ or $\mathrm{UCU}$, especially when transferring cultivars from one growing region to another. Unfortunately, chilling requirements are often only available in $\mathrm{CH}$ or UCU and thus probably not valid outside the location where they were determined. Our results suggest a new strategy for dealing with this problem. Known chilling requirements determined at a specific location should first be converted to $\mathrm{CP}$ using the site-specific conversion factor for the location of the experiment. The conversion factor can be obtained by determining winter chill with different metrics for several winter seasons and calculating the ratio between the results. The chilling requirement resulting from the conversion (then in $\mathrm{CP}$ ) should then be more reliable and more universally valid than the original $\mathrm{CH}$ or $\mathrm{UCU}$ estimate. If local industries in target growing regions are more comfortable with $\mathrm{CH}$ or $\mathrm{UCU}$, converting the $\mathrm{CP}$ requirement back into these units can then be done using the site-specific factors of the target region.

In using this strategy, however, one should keep in mind that conversion factors are not necessarily valid over time. According to the relationship between mean temperature and winter chill metric ratios (Fig. 5), temperature changes can shift these ratios. For six weather stations in California, Luedeling et al. (2009e) already detected a gradual decline of the ratio between $\mathrm{CH}$ and $\mathrm{CP}$ from 15 to under 12 between 1951 and 2008, in response to increasing winter temperatures. Assuming again that $\mathrm{CP}$ are a better measure of winter chill than $\mathrm{CH}$, such a shift would indicate that chilling requirements in $\mathrm{CH}$ that were valid in the 1950s are not necessarily valid today. For example, a chilling requirement of $50 \mathrm{CP}$ would correspond to $750 \mathrm{CH}$ in the 1950s and $600 \mathrm{CH}$ today. Using the full range of Safe Winter Chill ratios encountered during this time span indicates $\mathrm{CH}$-requirements ranging from 401 to $864 \mathrm{CH}$. It is thus necessary that trends in winter chill and in Safe Winter Chill ratios are observed and estimates adjusted accordingly, as the climate changes. The fruit and nut industry would also benefit from enhanced research efforts on winter chill and chilling requirements. At present, the physiological and genetic processes determining tree dormancy are inadequately understood, and their temperature responses have not been well characterized. Until much more functional understanding of these processes is gained, all winter chill models will only be proxies of the true biological processes. While all available models are useful for practical guidance of orchard management, they still leave a lot to be desired. In our opinion, more research on the effects of temperature on tree phenology, in particular during the dormancy season, is urgently needed, in order to prepare tree crop growers for the likely impacts of future climate change.

\section{Conclusions}

Our study showed that winter chill models are not equivalent, and that conversion factors between different winter chill metrics vary substantially around the globe. Data on chilling requirements should thus always be supplemented with information on the location, study duration and study conditions under which the requirements were determined. Only with this additional information will it be possible to compile data from various locations into a database that will be useful for matching tree cultivars with climate, a process that is likely to increase in importance as climate change accelerates.

Acknowledgments We greatly appreciate the help of Mikhail Semenov at Rothamsted Research, UK, for improving his LARSWG weather generator to suit our data processing needs. We also acknowledge support by Heiner Lieth at UC Davis, who provided computing power, and by Minghua Zhang, UC Davis, and the California Department for Food and Agriculture for supporting earlier work on winter chill models. We acknowledge the journal field editor and three anonymous reviewers for providing invaluable comments that greatly improved the manuscript.

Open Access This article is distributed under the terms of the Creative Commons Attribution Noncommercial License which permits any noncommercial use, distribution, and reproduction in any medium, provided the original author(s) and source are credited. 


\section{References}

Alburquerque N, García-Montiel F, Carrillo A, Burgos L (2008) Chilling and heat requirements of sweet cherry cultivars and the relationship between altitude and the probability of satisfying the chill requirements. Environ Exp Bot 64(2):162-170

Allan P et al (1997) Kiwifruit research in a subtropical area. Acta Hortic 444:37-42

Allan P, Rufus G, Linsley-Noakes GC, Matthee GW (1995) Winter chill models in a mild subtropical area and effects of constant $6^{\circ}$ C chilling on peach budbreak. Acta Hortic 409:9-17

Almorox J, Hontoria C, Benito M (2005) Statistical validation of daylength definitions for estimation of global solar radiation in Toledo, Spain. Energy Convers Manage 46(9-10):1465-1471

Balandier P, Bonhomme M, Rageau R, Capitan F, Parisot E (1993) Leaf bud endodormancy release in peach-trees - evaluation of temperature models in temperate and tropical climates. Agric For Meteorol 67(1-2):95-113

Baldocchi D, Wong S (2008) Accumulated winter chill is decreasing in the fruit growing regions of California. Clim Change 87:S153-S166

Chandler WH (1942) Deciduous orchards. Lea \& Febiger, Philadelphia

Chmielewski FM, Rötzer T (2001) Response of tree phenology to climate change across Europe. Agric For Meteorol 108(2):101-112

Chuine I (2000) A unified model for budburst of trees. J Theor Biol 207(3):337-347

Chuine I, Morin X, Bugmann H (2010) Warming, photoperiods, and tree phenology. Science 329(5989):277-278

Erez A (2000) Bud dormancy; phenomenon, problems and solutions in the tropics and subtropics. In: Erez A (ed) temperate fruit crops in warm climates. Kluwer, Dordrecht, pp 17-48

Erez A, Fishman S, Linsley-Noakes GC, Allan P (1990) The dynamic model for rest completion in peach buds. Acta Hortic 276:165-174

Fishman S, Erez A, Couvillon GA (1987a) The temperaturedependence of dormancy breaking in plants - computersimulation of processes studied under controlled temperatures. J Theor Biol 126(3):309-321

Fishman S, Erez A, Couvillon GA (1987b) The temperature dependence of dormancy breaking in plants: mathematical analysis of a two-step model involving a cooperative transition. J Theor Biol 124(4):473-483

Garcia-Mozo H, Mestre A, Galan C, Data C (2010) Phenological trends in southern Spain: a response to climate change. Agric For Meteorol 150(4):575-580

Gardner RAW, Bertling I (2005) Effect of winter chilling and paclobutrazol on floral bud production in Eucalyptus nitens. S Afr J Bot 71(2):238-249

Hudson LI (2010) Interdisciplinary approaches: towards new statistical methods for phenological studies. Clim Change 100(1):143-171

IPCC (2007) Climate Change 2007 - Synthesis Report. Contributions of Working Groups I, II and III to the Fourth Assessment Report of the Intergovernmental Panel on Climate Change. Intergovernmental Panel on Climate Change, Geneva, Switzerland.

Knight TA (1801) Account of some experiments on the ascent of the sap in trees. Philos Trans R Soc Lond 91:333-353

Körner C, Basler D (2010) Phenology under global warming. Science 327(5972):1461-1462

Linkosalo T, Lappalainen HK, Hari P (2008) A comparison of phenological models of leaf bud burst and flowering of boreal trees using independent observations. Tree Physiol 28(12):18731882

Linsley-Noakes GC, Allan P (1994) Comparison of 2 models for the prediction of rest completion in peaches. Sci Hortic 59(2):107-113

Linvill DE (1990) Calculating chilling hours and chill units from daily maximum and minimum temperature observations. Hortscience 25(1):14-16

Luedeling E, Blanke M, Gebauer J (2009a) Auswirkungen des Klimawandels auf die Verfügbarkeit von Kältewirkung (Chilling) für Obstgehölze in Deutschland. Erwerbs-Obstbau 51:81-94

Luedeling E, Gebauer J, Buerkert A (2009b) Climate change effects on winter chill for tree crops with chilling requirements on the Arabian Peninsula. Clim Change 96:219-237

Luedeling E, Zhang M, Girvetz EH (2009c) Climatic changes lead to declining winter chill for fruit and nut trees in California during 1950-2099. PLoS ONE 4(7):e6166

Luedeling E, Zhang M, Luedeling V, Girvetz EH (2009d) Sensitivity of winter chill models for fruit and nut trees to climate change. Agric Ecosyst Environ 133:23-31

Luedeling E, Zhang M, McGranahan G, Leslie C (2009e) Validation of winter chill models using historic records of walnut phenology. Agric For Meteorol 149:1854-1864

Menzel A et al (2006) European phenological response to climate change matches the warming pattern. Glob Chang Biol 12 (10):1969-1976

NCDC (2008) Database of the National Climatic Data Center. National Oceanic and Atmospheric Administration. http://www. noaa.gov/

Perez FJ, Ormeno NJ, Reynaert B, Rubio S (2008) Use of the dynamic model for the assessment of winter chilling in a temperate and a subtropical climatic zone of Chile. Chil J Agric Res 68:198-206

Richardson EA, Seeley SD, Walker DR (1974) A model for estimating the completion of rest for Redhaven and Elberta peach trees. Hortscience 9(4):331-332

Ruiz D, Campoy JA, Egea J (2006) Chilling requirements of apricot varieties. Acta Hortic 717:67-70

Ruiz D, Campoy JA, Egea J (2007) Chilling and heat requirements of apricot cultivars for flowering. Environ Exp Bot 61:254-263

Samish RM (1954) Dormancy in woody plants. Annu Rev Plant Physiol Plant Mol Biol 5:183-204

Saure MC (1985) Dormancy release in deciduous fruit trees. Hortic Rev 7:239-300

Schwartz MD (1999) Advancing to full bloom: planning phenological research for the 21st century. Int J Biometeorol 42(3):113-118

Semenov MA (2008) Simulation of extreme weather events by a stochastic weather generator. Clim Res 35(3):203-212

Shaltout AD, Unrath CR (1983) Rest completion prediction model for Starkrimson Delicious apples. J Am Soc Hortic Sci 108(6):957961

Spencer JW (1971) Fourier series representation of the position of the Sun. Search 2(5):172

Vegis A (1961) Samenkeimung und vegetative Entwicklung der Knospen. In: Ruhland W (ed) Handbuch der Pflanzenphysiologie, vol 16. Springer, Berlin, pp 168-298

Viti R et al (2010) Effect of climatic conditions on the overcoming of dormancy in apricot flower buds in two Mediterranean areas: Murcia (Spain) and Tuscany (Italy). Sci Hortic 124(2):217-224

Weinberger JH (1950) Chilling requirements of peach varieties. Proc Am Soc Hortic Sci 56:122-128 